https://oi.org/10.1007/s10694-020-00962-6

\title{
Introduction to the Special Section on Global Overview of Large Outdoor Fire Standards
}

\author{
* Samuel L. Manzello, Fire Research Division, National Institute of Standards \\ and Technology (NIST), Gaithersburg, MD, USA
}

\section{Overview}

Large outdoor fires have the potential to negatively impact the built environment. Wildland fires that spread into communities, known as wildland-urban interface (WUI) fires, have become a global problem. Significant WUI fires occurred in Australia in 2020, South Korea in 2019, and the USA in 2018. Large urban fires, including those that have occurred after earthquakes, are another example of large outdoor fires. Once a WUI fire reaches a community, a large urban fire may develop. A recent addition to the large outdoor fire problem is the rise of informal settlement fires, which are being seen in many countries.

On Sunday, October 7, 2018, a workshop sponsored by the International Standards Organization (ISO) under the topic of Fire Safety (ISO Technical Committee 92) occurred and was entitled ISO TC92 Workshop on Global Overview of Large Outdoor Fire Standards. Presentations were delivered related to national and regional summaries from across the globe on large outdoor fire standards intended to make communities less vulnerable to these fire exposures. A total of 35 global experts participated, representing Canada, France, Germany, Greece, Italy, Japan, Korea, New Zealand, Spain, Sweden, United Kingdom, and USA. Presenters highlighted knowledge gaps and specific standards needs in their regions. Details of the all presentations are listed in a NIST Special Publication that is free to access [1].

Papers were invited from the authors who delivered presentations, and upon the completion of peer-review, four papers are accepted and published in this special section of the journal Fire Technology. As part of the study discussed by Intini et al. [2], WUI codes and standards across multiple continents were sampled and described in detail. Gaps and inconsistencies in global WUI codes and standards are identified in their paper. Pastor et al. [3] present an overview of the WUI fire situation in Spain, highlighting current standards and codes shortcomings in Spain. Even though Spain is prone to many WUI fires each year, standard and codes are not well established in this country for WUI fire exposures. Baker et al. [4] provide an overview of WUI fire standards and codes in Oceania, with a spe-

\footnotetext{
* Correspondence should be addressed to: Samuel L. Manzello, E-mail: samuelm@nist.gov
} 
cial emphasis on Australia. In Japan, there is not a current WUI fire problem, but rather dangers exist due to the ever present threat of urban fire outbreaks. Yoshioka et al. [5] provide an overview of the large outdoor fire and the built environment situation in Japan.

Understanding from these national and regional summaries presented in these publications is being used as a basis for future work on this topic in ISO TC92. Specifically, there is a newly approved working group (WG), known as ISO TC92 WG14: Large Outdoor Fires and the Built Environment. The current charge of WG14 is to develop a technical report (TR) entitled TR-24188 Large Outdoor Fires and the Built Environment: Global Overview of Different Approaches to Standardization.

ISO TC92 WG14 is working closely with the permanent working group established by the International Association for Fire Safety Science (IAFSS) to bring the full depth of knowledge from the entire IAFSS community to the large outdoor fire problem [6]. The IAFSS permanent group is known as Large Outdoor Fires and the Built Environment (LOF\&BE) and readers are encouraged to join LOF\&BE 2020 that is being held on Saturday and Sunday (April 25, 2020 and April 26, 2020) before the 13th IAFSS Symposium in Waterloo, Canada. Improved interaction between the IAFSS academic research community and standards and codes community present in ISO TC92 is required to tackle the significant global large outdoor fire problem.

\section{Acknowledgements}

The support of the Netherlands Standardization Institute, known as NEN, is greatly appreciated as the local host for the ISO TC92 meetings. In particular, SLM would like to thank Dr. Rob Kotte of NEN for his support in setting up this workshop at the Westcord Hotel in Delft. SLM would also like to thank all the authors, participants, and reviewers that made this special issue a reality. Dr. Enrico Ronchi (Lund University, Sweden), Dr. Mohamad El Houssami (Plastics Europe, France), and Dr. Nourredine Bénichou (NRC, Canada) are appreciated for volunteering as the organizing committee on behalf of ISO TC92.

\section{References}

1. Manzello SL (2019) Summary of workshop on global overview of large outdoor fire standards. NIST Special Publication 1235. https://doi.org/10.6028/NIST.SP.1235

2. Intini P, Ronchi E, Gwynne S, Bénichou N (2020) Guidance on design and construction of the built environment against wildland urban interface fire hazard: a review. Fire Technol. https://doi.org/10.1007/s10694-019-00902-z

3. Pastor E, Muñoz J, Caballero D, Agueda A, Dalmau F, Planas E (2020) Wildland-urban interface fires in spain: summary of the policy framework and recommendations for improvement. Fire Technol. https://doi.org/10.1007/s10694-019-00883-z

4. Baker G, Webb A, Whiting P (2020) Regulatory controls for buildings in wildfire-prone areas of Australia. Fire Technol 
5. Yoshioka H, Himoto K, Kagiya K (2020) Large urban fires in Japan: history and management. Fire Technol

6. Manzello SL, McAllister S, Suzuki S (2018) Large outdoor fires and the built environment: objectives and goals of permanent working group. Fire Technol. https://doi.org/ 10.1007/s10694-018-0717-z

Publisher's Note Springer Nature remains neutral with regard to jurisdictional claims in published maps and institutional affiliations. 